\title{
Dulce María Loynaz, Fina García Marruz y la poesía de lo pequeño
}

Palabras clave: Dulce María Loynaz, Fina García Marruz, poesía, Isla de Cuba.

\section{Dos poetas cubanas}

Dulce María Loynaz y Fina García Marruz vivieron en Cuba desde principios del siglo XX, durante los años de la revolución y llegaron a los cambios finiseculares de la sociedad que transformaron las artes y las letras, sobre todo para una mujer que escribía versos. Un panorama común dio origen a dos grandes voces poéticas que se convirtieron en mitos de la Isla, cada una con sus rumbos y con una mirada hacia lo real muy subjetiva, a pesar de la influencia que grandes nombres de la literatura cubana e hispanoamericana ejercieron sobre ellas.

Dulce María Loynaz (1902-1997)1 fue amante de pocos discursos y de un silencio proficuo y compañero de la creación poética². Es autora de una poesía sencilla pero muy pensada en el tiempo, directa y nada altisonante, una autora que permaneció en su escritura a pesar de los cambios literarios debidos a las vanguardias del siglo XX. Siempre prefirió metros clásicos para sus versos y

1 Fue miembro de una importante familia de La Habana. Su padre, el general del Ejército Libertador Enrique, fue compositor de la letra del Himno Invasor. En 1987 se le concede el Premio Nacional de la Literatura y en 1992 fue la primera latinoamericana, y la segunda mujer ganadora del Premio Miguel de Cervantes, que recibió después de un silencio buscado voluntariamente. La Real Academia Española otorgó el premio sólo a dos cubanos, Dulce María Loynaz y Alejo Carpentier. Antes que ella, sólo la española María Zambrano lo había conseguido.

2 El goce del silencio es un elemento significativo en la escritura de Dulce María Loynaz, el placer de sugerir, más que decir, ha sido notado por muchos estudiosos; un ejemplo es el trabajo de Marilyn Bobes (1991). 
una conducta formal, no combativa, tanto en sus escritos, como en la vida social. Ya en la producción de los primeros años el lector percibe el diálogo con Dios que ella trata de establecer y que seguirá sordamente hasta el final, permeando su experiencia lírica.

La obra se compone de varias colecciones de poemas: Versos 1920-1938 (1938) es un libro donde se mezclan poemas de iniciación con fragmentos de mayor seguridad personal, Juegos de agua (1947) reúne versos más atentos, ligados a un tema que luego se convertirá en un símbolo propio, Poemas sin nombre (1953) y Últimos días de una casa (1958) son los trabajos de su más alta realización literaria, donde su mundo interior fluye libre, sin frenos ni equívocos, con un dominio estético muy apreciable. Poemas náufragos (1990) y Bestiarium (1991) cierran su producción lírica. También escribió una novela, Jardín (1951), un libro de crónicas, Un verano en Tenerife (1958), y un libro de memorias, Fe de vida (publicado en 1993).

La sencillez de una palabra poética abierta e inmediata se reencuentra en los versos de Fina García Marruz, como expresión de una lectura diferente de lo real. Frente a la poesía de lo íntimo reivindica la poesía de lo éxtimo ${ }^{3}$, si tomamos en préstamo un término psicoanalítico que se acerca mucho a lo que crea la autora. Fina Garciá Marruz ve la belleza del mundo que la rodea, de las cosas reales, y quiere escribir de ellas a través del tacto y de un lenguaje 'matérico', sin hermetismos. En su famoso ensayo confesional Hablar de la poesía (1986) afirma: «Nunca he sentido la belleza como una cualidad que puedan tener o no tener las cosas sino como su esencia constante [...] que puede revelárseme o no. [...]. La belleza, o lo es todo, o sería la misma cosa que la injusticia» (García Marruz, 1986).

Fina García Marruz (1923) es una de las voces poéticas vivas más audaces de la Isla, muchas veces considerada la poeta de la cubanidad por excelencia. Cercana al modernismo, estuvo en la pléyade de los jóvenes poetas que se relacionaron con Juan Ramón Jiménez durante la visita que el español realizó a Cuba, en 1936. Junto a su esposo y amigo Cintio Vitier y a Eliseo Diego, Fina García Marruz pertenecía a ese linaje poético que luego confluiría en el excepcional grupo de la revista Orígenes bajo la guía de José Lezama Lima. Como recuerda Alessandra Riccio, la escritora, junto a los origenistas, cultivó una poética de

3 Un artículo reciente de Jacques-Alain Miller (2010) nos recuerda que el vocablo extimidad es una invención del psiquiatra y filósofo francés Jacques Lacan: un término que se construye sobre intimidad. Lo éxtimo tiene en sí la característica de lo que está próximo, lo más interior, pero sin dejar de ser exterior. Se trata de una formulación paradójica. No es su contrario: la palabra indica que lo más íntimo está en el exterior, que es como un cuerpo extraño. 
resistencia animada por una racional fe cristiana que, por ejemplo, podemos leer en el poema Transfiguración de Jesús en el monte (1947) y por una diligencia que nunca se convierte en retórica (Riccio, 2011).

Fina García Marruz 4 fue escritora, poeta y ensayista, pero en el presente trabajo se tendrán en consideración las tres largas colecciones de poesía: Las miradas perdidas (1951) que, según la opinión de Eliseo Diego, es el libro que alcanza mayor unidad en toda la producción de la autora, el lugar «donde los poemas significan por sí mismos y, a la vez, están perfectamente imbricados en un conjunto mayor» (Rodríguez Gutiérrez, 2012); los temas miran atrás y al mismo tiempo al presente, (la niñez, los lugares primeros en la vida que regresan, sus sueños) propuestos no con nostalgia sentimental, sino envueltos en un aire de misterio que los convierte en inverosímiles; Visitaciones (1970) sigue las huellas de la obra anterior, pero con mayor madurez en el trabajo. Los asaltos del pasado a la memoria emergen más vívidos, impregnados por un hilo de nostalgia. Aquí Cuba y sus paisajes irrumpen con fuerza y en algunas partes los versos se disuelven, introduciendo el poema en prosa. Su última y más amplia creación es Habana del centro (1997), que incluye contenidos disímiles entre sí; como nos hace observar Carmen Ruiz Barrionuevo (2013) en su ensayo, este trabajo puede considerarse una summa poética por su circularidad, ya que reúne registros y asuntos del pasado y fija nuevos tonos y formas.

\section{La poesía que nace de lo pequeño}

Al acercarse a la obra de estas maestras de la poesía cubana, lo primero que sobresale son diferencias de sus versos, que nacen de impulsos distintos. Los estímulos que subyacen tras la obra poética de Dulce María Loynaz y de Fina García Marruz tienen que ver con la dimensión en que se origina su verso y con el propósito final que el proceso de escritura representa para su autor. En su autocrítica Dulce María Loynaz afirma:

El poeta -yo diría también que la poesía - como el árbol debe nacer dotado de impulso vertical y mientras más alto crece, menos se pierde en ramas [...]. La poesía como los árboles nace de la tierra y de ella ha de servirse, pero una vez nacida, no me parece propio que ande como los puercos, rastreando con ella. (Loynaz, 1991: 91)

4 Fue galardonada con distinciones de prestigio: el Premio Nacional de Literatura llega en 1990, el Premio Iberoamericano de Poesía Pablo Neruda en 2007 y el Premio Reina Sofía de Poesía Iberoamericana en 2011. 
Los poemas han de crecer de manera sencilla y natural, nacen de las cosas mínimas a las que la poeta dona un instinto de altura. Los temas ambiciosos no le gustan, lo pequeño se le revela más interesante y a través de la palabra poética éste se abre a otras posibilidades, más altas e inalcanzables. Alessandra Riccio (2013) define este proceso el efecto taumatúrgico de la poesía, porque es capaz de hacer prodigios y de provocar mutaciones con su energía generadora. La espiritualidad de Dulce María Loynaz avanza en cada palabra: es por y en la poesía que «damos el salto de la realidad visible a la invisible, el viaje alado y breve capaz de salvar en su misma brevedad la distancia existente entre el mundo que nos rodea y el mundo que está más allá de nuestros cinco sentidos» (Loynaz, 1991: 80). El trabajo del versificar se revela como una misión y cada poema es el fruto diligente de un tiempo destinado y consagrado a escuchar su propia alma.

Muchos críticos le atribuyen un itinerario poético hecho de paradojas: lo banal se mezcla con lo trascendente y la experiencia de acercamiento a la divinidad se establece a través del júbilo ofrecido por las cosas diarias. «Profesión de fe» (Versos 1920-1938) podría ser una explicación en versos de su pensamiento; los elementos de una naturaleza modesta y sencilla son protagonistas de un poema con forma de oración católica:

Creo en el cielo azul: (azul y cielo...)

Creo en la tierra humilde, en el precioso

don de la tierra tibia y fuerte, de la tierra bella.

Creo en el obscuro éxtasis del estanque; en la palabra buena que dijo alguien y en el ala

de oro

prometida

al gusano...

Creo en la Noche. Creo en el Silencio [...]

En los elementos humildes del universo, la tierra tibia, el obscuro estanque, el gusano, la poeta encuentra su motivo para rezar. Sus versos parecen anhelar a algo fugaz y delicado, al mismo tiempo construido con firmeza: citando al crítico Norge Espinosa (2012), la poeta «cultivó un aire de rareza que en algunas de sus estrofas ya estaba anunciada como convicción [...] su poesía es más fragancia que palabra fija, más sutileza que certeza». Una característica que probablemente nace en la predilección por el silencio y por una vida literaria apartada. Ella misma lo anuncia en «Premonición»: «Quedé amarga y sombría/ como niebla 
y retama [...] Dejadme sola todos. / Presiento que una cosa ancha y obscura/ y desolada viene sobre mí/ como la noche sobre la llanura...» (Loynaz, 1938). El significativo acercamiento noche-silencio que ya encontramos en el poema anterior aquí remite a una dimensión de soledad creada poco a poco a través de un abanico de adjetivos que crecen de intensidad, hasta que algo oscuro como la noche sobreviene y envuelve al sujeto - la poeta- en un aislamiento total.

Asimismo, en la obra de Fina García Marruz la desnuda y pobre realidad tiene un papel fundamental. La poesía es la dimensión ideal para descubrir y revelar, pero con una preocupación diferente: sus versos son una exploración borizontal -si se puede definir así en relación al instinto de altura de la obra de Dulce María- de lo sencillamente natural que, en la creación poética, adquiere un legendario prestigio, como sugiere el estudioso principal de la poeta, Jorge Luis Arcos en el prólogo a la Antología poética (2002).

En «Ama la superficie casta y triste», famoso soneto incluido en Las miradas perdidas, los primeros versos son la clave para conocer la poética de lo exterior que avanzará en toda su producción:

Ama la superificie casta y triste.

Lo profundo es lo que se manifiesta.

La playa lila, el traje aquel, la fiesta pobre y dichosa de lo que ahora existe.

Sé el que eres, que es ser el que tú eras, al ayer, no al mañana, el tiempo insiste, sé sabiendo que cuando nada seas de ti se ha de quedar lo que quisiste.

No mira Dios al que tú sabes que eres -la luz es ilusión, también locurasino la imagen tuya que prefieres, que lo que amas torna verdadera, y puesto que es así, sólo procura que tu máscara sea verdadera.

Lo profundo es lo que se manifiesta dice la poeta, no está en un espacio otro e inalcanzable que se desconoce, sino en la playa lila, en el traje aquel, en la superificie de las cosas y en las imágenes que aparecen. La realidad favorecida es la que se expresa en un tiempo presente, la materialidad que vemos, que abora existe, indagada a partir de la mirada. La poeta llega a la esencia más íntima de las cosas, que nunca pierden su corporeidad. 
La autora afirma: «La poesía no estaba para mí en lo nuevo desconocido sino en una dimensión nueva de lo conocido, o acaso, en una dimensión desconocida de lo evidente. Entonces trataba de reconstruir, a partir de aquella oquedad, el trasluz entrevisto, anunciador» (García Marruz, 1986). De ese vacío nace el deseo de una mayor presencia de lo real, porque «cierta revelación ha sido reconocible sólo a precio de desaparecer» (García Marruz, 1986). A partir de lo manifiesto, entonces, Fina García Marruz quiere llegar a lo que no se revela, y eso implica que todo lo exterior tiene en sí una trascendencia, tanto Dios como el ser humano. Roberto Fernández Retamar, en La poesía contemporánea en Cuba (1927-1953) (1954), la incluyó en los escritores trascendentalistas del grupo Orígenes mencionando la acepción de Heiddeger: «trascendente es lo que realiza el traspaso, aquello que traspasando, permanece» (Retamar 1954: 87). Y es justamente en Las miradas perdidas que la poeta desarrolla mejor el concepto de entrevisión en relación a la trascendencia, «no en lo que permanece siempre huyendo, / sino entre lo que, huyendo, permanece» (García Marruz, 2002) que es el núcleo de su pensamiento poético.

El boy bumilde, que es el verdadero alimento5 (García Marruz, 2002), también se viste de su ser femenino en un período en que el discurso literario dominante, en los primeros diez años de revolución, enfatizaba los grandes acontecimientos históricos. La poeta es muy explícita: «Que podamos tender la cama con la misma inspiración con que antes se iba a ver la caída del crepúsculo. La mujer que cose un roto, la que enciende el fuego, la que barre el polvo, contribuye también al orden del mundo» (García Marruz, 1986). La defensa de lo cotidiano se acerca a la defensa del trabajo diario de la mujer, que en sus versos ganará mayor resonancia y legitimidad social ${ }^{6}$. Como nos hace notar Katherine Hedeen (2008: 174), el punto de partida es el espacio no autorizado por los hombres, por ejemplo el interior de la casa o la cocina. En Visitaciones leemos: «allí es el habla/ más familiar, allí la lenta tarde/ cuela despacio, aromosa arde, / rumora entre las desiguales tazas» (García Marruz, 1970).

5 «El hoy humilde me parece el verdadero alimento. Pan nuestro de cada día, no lo excepcional, sino lo diario que no cansa, ni estraga, y que sustenta [...]. Que ningún acto que realicemos en el día, ni aún el más modesto, sea mecánico». (García Marruz, 2010)

6 Hasta los años '80 el boom no llegó para la escritura de las mujeres en la rica producción literaria cubana. Yañez escribe: «Ninguna de nosotras había participado en la guerra, ninguna todavía había tirado tiros, ninguna de nosotras había capturado a ningún bandido. Por lo tanto nadie podría escribir de eso». (Yáñez, 2000: 142) 


\section{La representación de la Isla}

En el ensayo Cuba attraverso le voci poetiche femminili Susanna Regazzoni (2009) nos señala la importancia de la actividad no sólo literaria sino también política de las mujeres, ya en tiempos remotos, en la formación de algunos valores de la identidad nacional cubana ${ }^{7}$. Leyendo algunos versos de dos grandes poetas cubanas del siglo XX la representación que Cuba tiene en su poesía es relevante: ella reside en el sentimiento de su ser isleño y en la manera en que, en los versos, la Isla acoge símbolos e imágenes. Ambas revelaron su cubanidad en sus obras, signo de una cercanía a la tierra natal, pero hay miradas distintas y acepciones que remiten a sentimientos opuestos, debidos especialmente a la manera de vivir Cuba y los controvertidos acontecimientos históricos y sociales: una más introspectiva y proclive a una escritura intimista, la otra más dispuesta a una poesía combativa y cubierta de alabanzas.

En la obra de Dulce María Loynaz, en muchas ocasiones su ser cubano se encuentra en el símbolo del agua. Aunque ya ha sido considerado en distintos trabajos críticos, será digno de interés observar los matices que la poeta del agua ${ }^{8}$ atribuye al elemento natural en relación con su tierra. El agua es símbolo y principio de vida que, lejos de estar prisonera en los juegos de la fuente, sugeridos en el título engañador de Juegos de agua, se libra y deshace las fronteras ornamentales a las que parece destinada, sale e inunda el mundo que la rodea, y será libre como la poeta en su poesía. Un ejemplo aparece en los primeros versos de «Al Almendares», río habanero: «Este río de nombre musical / llega a mi corazón por un camino... [...]» y la defensa de ello surge al final: «Yo no diré qué mano me lo arranca, / ni de qué piedra de mi pecho nace: / Yo no diré que él sea el más hermoso... / ¡Pero es mi río, mi país, mi sangre!» (Loynaz, 1947). Algunos críticos ven en estos versos una declaración de amor para su ciudad, La Habana, más que para la Isla9.

$7 \quad$ Las primeras obras de la literatura cubana en que los lectores pueden entrever un inicio de conciencia de identidad fueron escritas por mujeres, que anticipan ese sentimiento de cubanidad convertido en factor central sólo un siglo después en la costrucción de la identidad nacional. Son dos textos escritos por una o más mujeres, después de la derrota sufrida por La Habana contra el ejercito inglés: Memorial dirigido a Carlos III por las señoras de La Habana en 25 de agosto de 1762, y la Dolorosa métrica espresión del sitio y entrega de La Habana, dirigida a N.C. Dn. Carlos Tercero que Ds. Gua sin indicación de autor. Éstos ya testimonian la intensa actividad política y social femenina en la creación de valores nacionales (Regazzoni, 2009).

8 Ella fue definida poeta del agua por el papel predominante que ésta tiene en muchas colecciones poéticas, primera entre todas Juegos de agua.

9 Lo sugiere Zaida Capote en su escrito «El arte de la paradoja: la poesía de Dulce María Loynaz» (1998). 
En el poema «Isla», en cambio, la imagen del agua adquiere rumbos antitéticos, es al mismo tiempo un objeto peligroso y un elemento homenajeado. Hay una sustitución del sujeto lírico, es la misma Isla que toma la palabra. La variación del yo hablante, que no guarda la distancia con el entorno como ocurre con el río Almendares, es pura identificación entre la poeta y la naturaleza vivida, en que la distinción no resulta fácil:

Rodeada de mar por todas partes, soy isla asida al tallo de los vientos...

Nadie escucha mi voz si rezo o grito:

Puedo volar o hundirme... Puedo, a veces, morder mi cola en signo de Infinito.

Soy tierra desgajándose... Hay momentos en que el agua me ciega y me acobarda, en que el agua es la muerte donde floto... Pero abierta a mareas y a ciclones, hinco en el mar raíz de pecho roto. Crezco del mar y muero de él... Me alzo ipara volverme en nudos desatados...! ¡Me come un mar batido por las alas de arcángeles sin cielo, naufragados!

Se trata de una tierra desgarrada por el mar, a veces olvidada. Esa compenetración de los yoes hablantes es quizás una manera sincera de interrogar su ser isleño, que aquí se siente orgulloso y también desplazado en su Isla: es una tierra que crece del mar y muere de él, un mar que ciega y acobarda, donde volar o hundirse, hasta naufragar y perder $\mathrm{pie}^{10}$. El poema «Naufragio» permanece en el concepto y lo lleva al extremo opuesto, en un vacío trágico que también es ausencia del amado: «iQué bracear de náufrago / y qué hundirse [...]/ ¡Ay qué mar sin riberas ni horizonte, / [...] ¡Qué tragar sal y muerte en esta / ausencia / infinita de ti!» (Loynaz, 1947).

En la poesía de Fina García Marruz su cubanidad se construye mediante la apropiación espacial desde la perspectiva de género. Muchas veces la voz

10 En la Cuba del siglo XX recordamos otra representación de una isla rodeada por un agua amenazadora que revela un aspecto más desmitificador e infernal de la tierra cubana: La isla en peso de Virglio Piñera (1943: 1) es el mayor ejemplo del realismo sin idealizaciones y de la poética negadora del autor, quien elige un lenguaje seco y frío para su propósito y que es signo de su sentirse en prisión. El poema así empieza: «La maldita circunstancia del agua por todas partes / me obliga a sentarme en la mesa del café. / Si no pensara que el agua me rodea como un cáncer / hubiera podido dormir a pierna suelta». 
poética se encuentra en lugares de mujeres y de allí habla, como se lee en el poema «En la luz, solamente», en Habana del centro: «No de otro sitio / que de mi ciudad podría / ser éste: veo / los interiores de las casas, el dulce / pasillo lateral, / la jaula del canario / pobre, en la pared de afuera / de la cocina [..].» (García Marruz, 1997). La ciudad de La Habana se refleja en el espacio cotidiano femenino, hasta quizás convertirse en un solo elemento. Lo mismo se lee en «Azules», incluido en Visitaciones; en este caso la identificación se realiza con toda Cuba: «Y el azul, el azul de la portada, /lechoso, inconfundible, repetido / mil veces, en el fragrante hueco / del otro azul, toda la patria» (García Marruz 2011: 155).

En otros versos el cotidiano no es el tema principal, pero la nación aparece de manera explícita como en un himno. En «Su ligereza de colibrí, su tornasol, su mimbre», en la colección Visitaciones del año 1970 (Ruiz Barronuevo, 2011: 167) Cuba goza de una representación expresiva, es el centro de un retrato en que desfilan imágenes que podrían parecer contradictorias, pero que encuentran una armonía bien articulada y justificada en el ser femenino de la poeta. Los rasgos de la Isla, que también son su fuerza, se trasforman en características femeninas que la poeta admira y defiende: «su suavidad de hierro indoblegable, su vivir, como el pájaro, en el instante, la maderita débil de sus juguetes y paredes, su sobrepensamiento burlón y corto / de las afirmaciones enfáticas, aunque ligeras, de / lo diario, su amor a la estravagancia y rareza personal» (Ruiz Barronuevo, 2011: 167). Los últimos versos se impregnan de una sensibilidad femenina intensa, la voz lírica se convierte en la más comunicativa y construye una sutil identificación entre la Isla y la mujer: «Lo insondable de su irresponsabilidad / capaz de originar la chispa que incendie el / universo / sin ningún plan previsto, / la imposibilidad de culpar la culpa de ese rostro / que sonríe a la nada y habla de su madre con / cariño» (García Marruz, 1970).

\section{$4 \quad$ Las imágenes del recuerdo}

Los recuerdos ocupan un papel fundamental: se expresan a través de distintas imágenes y acompañan a la memoria del sujeto lírico en un recorrido personal hacia espacios y tiempos queridos u otras evocaciones lejanas. Cada una de éstas participan en el universo simbólico interior de la autora.

En el poema «El espejo» (Juegos de agua, 1947) de Dulce María Loynaz, la temática del agua vuelve y, extendida a la metáfora del espejo, es motivo para recordar y mirar al pasado con melancolía: «Este espejo colgado a la pared / 
donde a veces me miro de pasada... / es un estanque muerto que han traído / a la casa [...] Agua inmóvil y rígida que guarda / dentro de ella colores todavía / remembranzas de sol» (Loynaz, 1947). La poeta construye una dicotomía aguaespejo que toma atributos diferentes según el tiempo del recuerdo: es «un agua amansada por la muerte» en el tiempo presente $\mathrm{y}$ «un agua viva, abierta al viento alegre que la hacía bailar» en un tiempo que pudo haber sido, citando al crítico Leonardo Sancho Dobles en su análisis de la composición (Sancho Dobles, 2007). Las imágenes despertadas en el ánimo del yo lírico en el tiempo presente y reflejadas en este agua-espejo, que se parece a un cadáver, están cargadas de sentidos negativos. La vitalidad de un tiempo pasado, en cambio, ahora se convierte en un recuerdo que desorienta. Después de mirarse en un espejo gris, casi un fantasma, y de contemplarse estática, la voz lírica parece miedosa, porque es consciente del tiempo que se ha ido. En los versos finales, en un clímax de elocuentes imágenes pertenecientes al nivel semántico de las cosas humildes, aparece el temor de «quedarse allí dentro por siempre... Despegada de sí misma, perdida en ese légamo de cenizas de estrellas apagada» (Loynaz, 1947).

También leemos del recuerdo de una felicidad perdida en el largo poema «Ú1timos días de una casa» (1958) en que la poeta se desdobla en su propia casa: el yo hablante toma voz y forma de ésta, se siente viejo y abandonado como ella, en edad avanzada, cercana a la muerte, y recuerda con nostalgia tiempos pasados en alegría. Hay una identificación completa entre el sujeto lírico y el objeto, el agotamiento del cuerpo femenino pasa por el desmoronamiento de la casa donde vivió. Y ésta no es sólo un lugar, un tiempo habitado, es un espacio que guarda la memoria familiar y de aquellos que la visitaron. El tono sube lentamente, desde una perplejidad inicial hacia la angustia final por el acercarse de la muerte. Al principio la voz lírica confiesa: «Cae la noche / y yo empiezo a sentir no sé qué miedo:/ miedo de este silencio, de esta calma», y anticipa su preocupación apremiante: «Otro día ha pasado y nadie se me acerca. /Me siento ya una casa enferma». Surgen recuerdos pasados que aumentan la conciencia de soledad: «Nadie puede decir /que he sido yo una casa silenciosa; / [...] las risas y los cantos de los jóvenes /y aquella efervescencia de la vida / que ha borbotado siempre en mis / ventanas / como en los ojos de / las mujeres enamoradas». En todas las cuatro jornadas en que el poema está divido, el silencio es una presencia constante que acomapaña a la agonía de un cuerpo moribundo.

Los recuerdos de acontecimientos ocurridos a lo largo de una vida reaparecen en Visitaciones de Fina García Marruz, en el poema que da el título a la 
colección, donde el sujeto lírico es consciente de la muerte próxima. Son como relámpagos que sobrevienen en la memoria y que regalan deleite en el momento de la evocación. Como Dulce María Loynaz, Fina García Marruz elige un lugar querido a sus recuerdos porque reúne en sí mismo «días, rostros, sucesos que supieron recorrer el camino de nuestro corazón» (García Marruz 2011: 184). Es la casa de la infancia, que hace revivir experiencias y gestos pasados, inexplicables a los ojos de los demás:

Cuando el tiempo ya es ido, uno retorna como a la casa de la infancia [...]

Vuelven de nuevo los cansados pasos cada vez más sencillos y más lentos, al mismo día, el mismo amigo, el mismo viejo sol. Y queremos contar la maravilla ciega para los otros, a nuestros ojos clara en donde la memoria ha detenido como un pintor, un gesto de la mano, una sonrisa un modo breve de saludar.

Poco a poco los recuerdos se trasforman en imágenes vívidas, adquieren sustancia material y en los últimos versos, cuando la muerte está percibida con intensidad, el tacto del yo lírico vuelve a ser el único método posible para medir su presencia en el mundo: «Pues poco a poco el mundo se vuelve /impenetrable, /los ojos no comprenden, la mano ya no toca / el alimento innombrale, lo real» (García Marruz, 2011: 184). Lo real se presenta otra vez como alimento, ese necesario pan que nos sustenta cada día y en que la escritora pone las raíces de su pensamiento poético.

\section{Conclusión}

Ambas poetas, en el tiempo de la construcción de la obra, realizan un camino singular en el panorama literario de la época, a través de imágenes y símbolos. En una lectura preliminar de los versos emerge una manera opuesta de entender la poesía, que, sin embargo, brota de afanes similares, construidos con un imaginario femenino muy comunicativo y subjetivo. Por distintas razones y en su específico itinerario, Dulce María Loynaz y Fina García Marruz quisieron dar una señal fuerte a su discurso poético, lejos de la norma patriarcal que predominaba en ese período. 
La introspección de Dulce María Loynaz que, al mismo tiempo, rescata la esencia del hombre y de la mujer por ser seres humanos en igual manera y la honda relación entre cuerpo-materialidad y espíritu que profesa Fina García Marruz son dos rutas diferentes para tratar una ideología personal, en una dimensión poética que recupera la más pequeña naturaleza.

\section{Bibliografía}

Barnet, M. (2002): «En una mano un látigo; en la otra, una flor». La Jiribilla, 85: http://www.lajiribilla.co.cu/2002/n85_diciembre/2020_85.html (29-06-2015).

Bobes, M. (2012): «Dulce María Loynaz y el canto del cisne». La Jiribilla, año X: http://www.lajiribilla.co.cu/2012/n573_04/573_02.html (28-06-2015).

Bobes, M. (1991): «La poesía del silencio». En: Simón, P.: Valoración multiple: Dulce María Loynaz. La Habana: Casa de las Américas, 213-221.

Capote, Z. (1998): «El arte de la paradoja: la poesía de Dulce María Loynaz». En: Campuzano, L. (coord): Mujeres Latinoamericanas del siglo XX. Historia y Cultura. La Habana/México: Casa de las Américas/UAM-Iztapalapa, tomo I, 75-93.

Elizalde, R. M. (2007): «Fina García Marruz: Me comunico mejor con el silencio». La Jiribilla, año V: http://www.lajiribilla.cu/2007/n307_03/307_01. html (29-06-2015).

Espinosa, N. (2012): «Dulce María Loynaz: el verso como carácter». La Jiribilla, año X: http://www.lajiribilla.cu/2012/n573_04/573_28.html (01-07-2015).

García Marruz, F. (2002): Antología poética, selección y prólogo de Jorge Luis Arcos. México D. F.: Fondo de Cultura Económica.

García Marruz, F. (1986): Hablar de la poesía. La Habana: Letras Cubanas.

Hedeen, K. (2008): «La cubana en la poesía: género y nación en Visitaciones y Habana del centro de Fina García Marruz». Revista Iberoamericana, Vol. LXXV, 226, 167-189.

Lemes Batista, A. (2003): «Dulce María Loynaz: una excelsa intelectual cubana». La Jiribilla, 107: http://www.lajiribilla.co.cu/2003/n107_05/107_04. html (27-06-2015).

Loynaz, D. M. (1991): «Mi poesía: autocrítica». En: Simón, P. Valoración multiple: Dulce María Loynaz. La Habana: Casa de las Américas, 80-81. 
Loynaz, D. M. (1955): Obra lírica: versos (1920-1938). Juegos de agua. Poemas sin nombre. Madrid: Aguilar (Ograma).

Loynaz, D. M. (1938): Versos 1920-1938. La Habana: Ucar, García y Cia.

Méndez Martinez, R. (2012): «Dulce María en la otra primavera». La Jiribilla, año X: http://www.lajiribilla.co.cu/2012/n573_04/573_11.html (29-06-2015).

Miller, J.A. (2010): «Más interior que lo más íntimo». Página/12: http:// www.pagina12.com.ar/diario/psicologia/subnotas/143452-461252010-04-08.html (28-06-2015).

Núñez, V. R. (2001): «Dulce María Loynaz: yo amo el silencio». La Jiribilla, 17: http://www.lajiribilla.co.cu/2001/n17_agosto/527_17.html (01-07-2015).

Núñez García, X. F. (2003): «Una mirada a la diferencia. A propósito del pensamiento humanista de Dulce María Loynaz». Revista ISLAS, 45. La Habana: Editorial Universitaria, 6o-70.

Penalva, J. J. (2002): «Tres variaciones sobre el tema de la casa: Leopoldo Panero, Luis Rosales y Dulce María Loynaz». América sin nombre, 3, 48-55.

Piñera, V. (1943): La isla en peso; un poema. La Habana: Tipografía García.

Puppo M. L. (2006): «Floración de un nuevo mundo: la poetisa americana en los ensayos de Dulce María Loynaz». Rilce. Revista de Filología Hispánica, 22, $105-124$.

Regazzoni, S. (2009): «Cuba attraverso le voci poetiche femminili». Oltreoceano. Rivista sulle migrazioni. Udine: Forum Editrice.

Retamar, R. F. (1954): La poesía contemporánea en Cuba (1927-1953). La Habana: Ed. Orígenes.

Riccio, A. (2003): «Dulce María Loynaz: la poesía como taumaturgia». Archivo Cubano: http://www.archivocubano.org/loynaz_02.html (10-07-2015).

Riccio, A. (2011): «Quattro poetesse cubane: Fina García Marruz, Basilia Papastamatíu, Nancy Morejón e Reina María Rodríguez». Cuba. Un'identità in movimento. Archivo Cubano: http://www.archivocubano.org/riccio_ poetesse.html (03-07-2015).

Rodríguez Gutiérrez, M. (2012): «Las miradas perdidas de Fina García Marruz». La Estafeta del viento, revista de poesía de la Casa de América, segunda época: http://www.laestafetadelviento.es/articulos/meditaciones/las-miradas-perdidas-de-fina-garcia-marruz (26-06-2015). 
Ruiz Barronuevo, C. (2011) (Edición e introducción). Fina García Marruz. ¿De qué, silencio, eres tú silencio?. Ediciones Universidad de Salamanca.

Ruiz Barrionuevo, C. (2013): «Habana del centro, summa poética de Fina García Marruz». Guaraguao. Revista de Cultura Latinoamericana, año 17, 43, 17-39.

Russotto, M. (2002) «Casa, cuerpo, pasión. Una lectura de "Ultimos días de una casa" de Dulce María Loynaz». Ciberletras: Revista de crítica literaria y de cultura, 7: http://www.lehman.cuny.edu/ciberletras/vo7/russotto.html (25-06-2015).

Sancho Dobles, L. (2007): «Dulce María Loynaz: una imagen inasible». Espéculo. Revista de estudios literarios, 36: http://pendientedemigracion.ucm.es/ info/especulo/numero36/inasible.html (28-06-2015).

Serra Maiorana, G. (2007): «Lo religioso en la poesía de Fina García Marruz», Espéculo. Revistade estudiosliterarios, n.36, Universidad Complutense de Madrid: https://pendientedemigracion.ucm.es/info/especulo/numero36/finagma .html_(28-06-2015)

Yáñez, M. (2000): Cubanas a capitulo. Santiago de Cuba: Oriente. 


\section{Fabiola Cecere}

University Ca' Foscari of Venice

\section{Dulce María Loynaz, Fina García Marruz and the poetry of littleness}

Keywords: Dulce María Loynaz, Fina García Marruz, poetry, Cuba Island.

Dulce María Loynaz and Fina García Marruz are two poets who stand out in the rich heritage of Cuban literature for the linguistic vitality of their verses, their vivid images, their evocative use of language and for embodying, in their own way, the life history, customs, contradictions and all the glorious colour of the island. We shall explore some of the poetic questions and themes debated by the authors in the poems. They reveal an antithetical conception of poetry but, at same time, a common root. The comparative analysis will reflect on the linguistic rigour choosen by Dulce María Loynaz in her lyric intimacy, on the hand and on Fina García Marruz's pursuit of the eternal in the fleeting temporal things. 


\section{Fabiola Cecere}

Univerza Ca' Foscari v Benetkah

\section{Dulce María Loynaz, Fina García Marruz in poezija majhnega}

Ključne besede: Dulce María Loynaz, Fina García Marruz, poezija, otok Kuba

Dulce María Loynaz in Fina García Marruz sta pesnici, ki v bogati kulturni panorami kubanske književnosti izstopata po jezikovni moči verzov, živahnih podobah, slikanju z besedami in po tem, da na svojstven način doživljata otok, njegovo zgodovino, običaje, protislovja in barve. Ta prispevek skuša ponuditi pregled nekaterih pesniških preizpraševanj in najpogostejših tematik, ki se pojavljajo v poeziji omenjenih avtoric in razkrivajo antitetični razvoj njunega pesniškega izraza, čeprav imata pogosto skupen izvor. Primerjalna analiza razkrije jezikovno preciznost Dulce Maríe Loynaz, avtorice očitno intimistične poezije, ter iskanje večnega v minljivosti materialnega, k čemur stremi Fina García Marruz. 